Научная статья

УДК 689

DOI https://doi.org/10.24866/VVSU/2073-3984/2021-4/177-188

Л.А. Королева ${ }^{1}$

А.В. Подшивалова ${ }^{2}$

Владивостокский государственный университет экономики и сервиса

Владивосток. Россия

\title{
Разработка способа изготовления украшения с микровышивкой с высокими эстетическими и эксплуатационными характеристиками
}

\begin{abstract}
Аннотация. Микровышивка во все времена считалась искусством, поэтому многие изделия до сих пор хранятся в музеях. В настоящее время техника микровышивки очень активно применяется в изготовлении украшений и декора, подчеркивающих стиль, изысканный вкус и женственность. Актуальность данной работы заключается в разработке эффективного способа изготовления украшения с микровышивкой с высокими эстетическими и эксплуатационными характеристиками. В ходе исследования проанализированы разные способы изготовления украшений (на примере броши) с микровышивкой с использованием: специализированной металлической фурнитуры, состоящей из трех частей (внешней рамки, кабошона и задника); металлической фурнитуры с лотком для вставки (2 варианта). В результате установлено, что общим недостатком описанных способов является отсутствие какой-либо защиты вставки с вышивкой от внешних загрязнений в процессе эксплуатации украшений (многочисленные прикосновения рук, влага, пыль). Практическая значимость предлагаемого способа заключается в разработке технологии изготовления текстильной вставки с вышивкой и непосредственно сборки украшения с защитным покрытием от загрязнений. Указанный технический результат достигнут способом изготовления текстильной вставки с микровышивкой, пакет которой состоит из основного материала, прокладок из материала с односторонним клеевым покрытием и отделочной нитки. Полученные результаты также позволяют более экономично расходовать основной материал (ткани для вышивки), осуществлять защиту от загрязнений поверхности украшения посредством покрытия микровышивки текстурированным гелем, при этом цвета и полутона вышивки приобретают более глубокую насыщенность. Гель является
\end{abstract}

1 Королева Людмила Анатольевна - канд. техн. наук, доцент, доцент кафедры сервисных технологий. ORCID: https://orcid.org/0000-0002-6916-7613; e-mail: lyudmila.koroleva1@vvsu.ru

2 Подшивалова Анна Владимировна - канд. техн. наук, доцент кафедры сервисных технологий. ORCID: https://orcid.org/0000-0002-8083-857X; e-mail: av.podshivalova@vvsu.ru 
дополнительной защитой изображения от возможных ссадин и других повреждений в процессе его “жизни». За счет использования в изготовлении броши отделочной нитки также возможно применение более вариативного художественного оформления украшений.

Ключевые слова: вышивка, микровышивка, украшения, броши, текстильная вставка, отделочная нитка.

L.A. Koroleva

A.V. Podshivalova

Vladivostok State University of Economics and Service

Vladivostok. Russia

\title{
Development of a method for manufacturing micro-embroidered jewelry with high aesthetic and operational characteristics
}

\begin{abstract}
Micro-embroidery was considered art at all times, so many products are still kept in museums. Currently, the micro-embroidery technique is very actively used in the manufacture of jewelry and decor that emphasize style, exquisite taste and femininity. The relevance of this work lies in the development of an effective method for making jewelry with microembroidery with high aesthetic and operational characteristics. In the course of the study, various methods of making jewelry (for example, a brooch) with micro-embroidery were analyzed using: specialized metal fittings, consisting of three parts: an outer frame, a cabochon and a backdrop; metal fittings with an insert tray ( 2 options). As a result, it was found that the general disadvantage of the described methods is the absence of any protection of the insert with embroidery from external contamination during the operation of the jewelry (numerous hand touches, moisture, dust). The practical significance of the proposed method lies in the development of a technology for manufacturing a textile insert with embroidery and directly assembling jewelry with a protective coating against contamination. The specified technical result is achieved by the method of manufacturing a textile insert with micro-embroidery, the package of which consists of a base material, spacers from a material with a one-sided adhesive coating and a finishing thread. The results obtained also make it possible to use the main material (fabrics for embroidery) more economically, to protect the decoration surface from dirt by coating the micro-embroidery with textured gel, while the colors and halftones of the embroidery acquire deeper saturation. The gel is an additional protection of the image from possible abrasions and other damages during its "life". Due to the use of a finishing thread in the manufacture of a brooch, it is also possible to use a more varied decoration of jewelry.
\end{abstract}

Keywords: embroidery, micro-embroidery, jewelry, brooches, textile insert, finishing thread.

\section{Введение}

В продуктах человеческой деятельности прекрасное выступает как проявление и, следовательно, как свидетельство целесообразности и совершенства [1]. Подтверждением данного тезиса является искусство вышивания, практикуемое на протяжении многих столетий. В вышивке все имеет эстетически-смысловое 
наполнение. Мировоззренческими идеями наполнены не только почитаемые произведения искусства с вышивкой, но и бытовые предметы, одежда, украшения и аксессуары [2].

Занятие вышивкой известно с древних времен, но особенно следует выделить микровышивку (от фр. petit point - маленькая точка, мелочь, что-то мелкое). Каждый стежок выполняется размером меньше миллиметра и напоминает точки из ниток, отсюда и название. Готовая работа может насчитывать более 400 стежков на 1 кв. см. Каждый стежок может иметь размер менее миллиметра, поэтому полноценный узор состоит из массы крохотных точек. Такой вид вышивки во все времена считался искусством, поэтому многие изделия до сих пор хранятся в музеях $[3,4]$.

Ручная вышивка, а особенно микровышивка, всегда являлась занятием именитых особ благородных сословий. В технике petit point вышивали короли и королевы, среди них Екатерина Медичи, Мария Стюарт, Мария-Антуанетта и многие другие царственные, королевские особы.

История украшений и вышивок костюма - это история культуры народа в определенную историческую эпоху. Сегодня вышивание существует как вид современного рукоделия, а в форме аутентичного бытования во времена революций и репрессий, в военные и поствоенные годы утратило свои отличительные орнаментальные и художественно-технологические традиции, которые присущи культуре еще в начале XX века. Утратив естественный ход существования и прямую преемственность от матери дочери с детства, крохотные ростки традиций вышивания начали появляться снова на качественном жизнеспособном уровне существования с начала 1980-х годов. Современные мастера стали искать, сохранять и изучать художественные ценности вышитого текстиля, реконструировать ранее используемые приемы и техники вышивки. Уникальный современный опыт изучения традиций позволяет создавать доподлинные реплики артефактов с вышитыми орнаментами, которые сохранились в музейных фондах или остались чудом в наследство потомкам $[5,6]$, а также актуальную модную одежду, украшения и аксессуары, в том числе с микровышивкой.

\section{Основная часть}

В настоящее время техника микровышивки очень активно применяется в изготовлении украшений и декора [7], подчеркивающих стиль, изысканный вкус и женственность. К ним относятся серьги и кольца, кулоны и броши, браслеты и заколки, карманные зеркала, кошельки, косметички и др. Практикуют несколько способов изготовления таких украшений, как броши, серьги, браслеты, имеющих ряд достоинств и недостатков.

Известен способ изготовления украшения с использованием специализированной металлической фурнитуры, состоящей из трех частей: внешней рамки, кабошона и задника (рис. 1) [8]. 


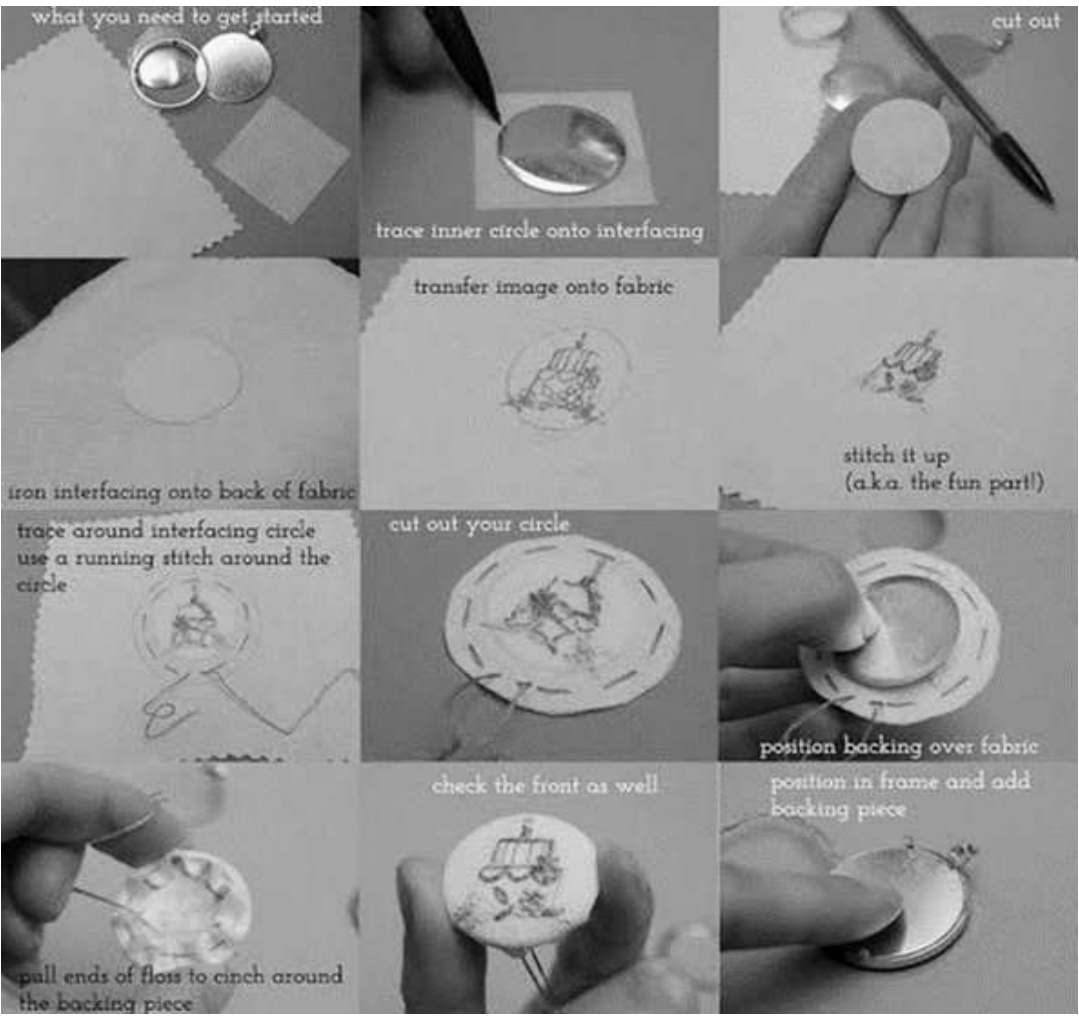

Рис. 1. Способ изготовления украшения с микровышивкой с использованием специализированной металлической фурнитуры

Согласно этому способу на ткани выполняют вышивку, затем намечают контур в соответствии с размерами кабошона; примерно на расстоянии 5 мм от намеченного контура прокладывают ручную строчку прямыми стежками, далее вырезают деталь по линии, отстоящей от проложенной строчки еще на 5 мм. 3атем кабошон размещают с изнаночной стороны вырезанной детали, по центру, и стягивают строчку таким образом, чтобы кабошон был ровно обтянут тканью и вышитый элемент располагался строго по центру; нитку закрепляют и обрезают. Далее обтянутый кабошон вставляют в рамку, закрывают деталью задника и зажимают задник лапками, расположенными на детали рамки. Однако описанная специализированная фурнитура имеет ограниченное модельное и ассортиментное (использование не для всех видов украшений) разнообразие, труднодоступна для приобретения и имеет более высокую стоимость. Наличие припусков на обтягивание кабошона также приводит к увеличению расхода ткани для вышивки.

Фурнитура из металла или дерева, состоящая из одной детали с лотком для вставки, имеет разнообразный дизайн, доступна для приобретения; ее стоимость более низкая. Собрать украшение с помощью такой фурнитуры возможно двумя способами: вклеить ткань с вышивкой в лоток или обтянуть тканью с вышивкой изготовленный промышленным способом кабошон (или вырезанный самостоя- 
тельно из картона) и вклеить в лоток. Не всегда возможно обеспечить точное совпадение размера лотка и готового кабошона. Кроме того, использование готовых кабошонов из стекла увеличит вес изделия и потребует навыков в процессе обтягивания, поскольку поверхность очень гладкая и ткань скользит по ней. Возможно изготовить кабошон под любой размер лотка (вырезать из картона), но при попадании украшения во влажную среду его внешний вид может ухудшиться. Этот способ самостоятельного изготовления кабошона также предполагает очень точную линию среза, что вручную сделать непросто. Малейшая неровность будет заметна после обтягивания тканью и испортит внешний вид изделия. Обтянутый кабошон должен точно и свободно входить в лоток для вставки. Погрешность в 0,5 мм уже будет заметна.

Известен способ изготовления украшения с микровышивкой, описанный в журнале «Вышиванка», с использованием металлической фурнитуры с лотком для вставки (рис. 2) [9].

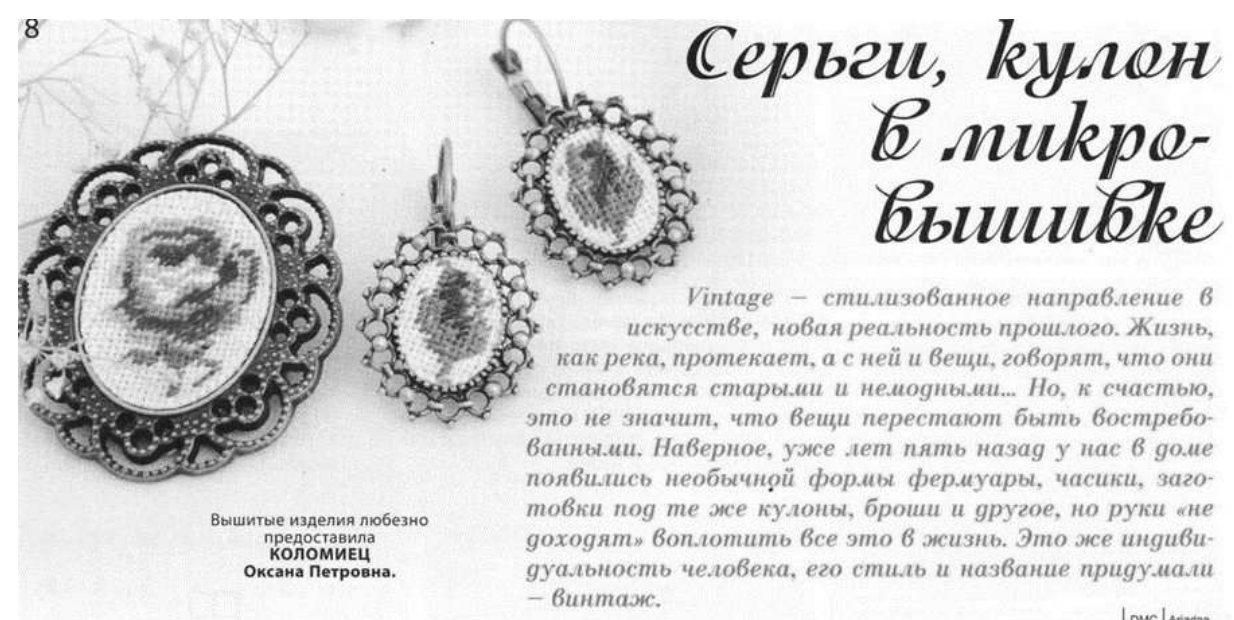

Уровень сложности: 的今占

Материалы: 10 × $10 \mathrm{~cm}$ хлопчатобумажной ткани полотняного плетения, хлопчатобумажные нити мулине DMC, иголка, ножницы, универсальный клей, две заготовки для сережек и для кулона.

Техника вышивки: гобеленовый стежок за одну нить ткани (смотрите страницы 6, 7).

Описание работы: по внутреннему размеру заготовки сережек и кулона вышейте на ткани три узора (схемы 1, 2). Вышивки постирайте, подкрахмальте, отутюжьте с изнаночной стороны на мягкой подкладке. Вырежьте их по внутреннему размеру заготовок и с помощью универсального клея приклейте к заготовке. Края аккуратно заправьте.

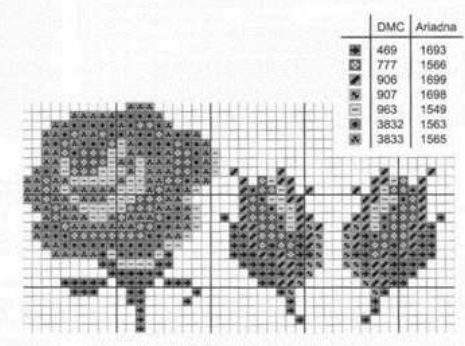

Рис. 2. Способ изготовления украшения с микровышивкой, описанный в журнале

«Вышиванка», с использованием металлической фурнитуры с лотком для вставки

Для осуществления известного способа на ткани выполняют вышивку, ткань с вышитыми элементами стирают, крахмалят, утюжат с изнаночной стороны на мягкой подкладке. Затем вырезают вышитые элементы по размеру вставки в металлической фурнитуре и приклеивают их, края аккуратно заправляют. При этом остается высокая вероятность проникновения клея на лицевую сторону ткани 
с вышивкой; незакрытый стык металлической фурнитуры и среза ткани ухудшает эстетические характеристики изделия; ткань не стабилизирована, что может привести к осыпаемости среза и подвижности ее структуры, то есть к искажению вышитого изображения.

Известен еще один способ изготовления украшений с микровышивкой, также с использованием металлической фурнитуры с лотком для вставки (рис. 3) [10].

\section{Ausführung:}

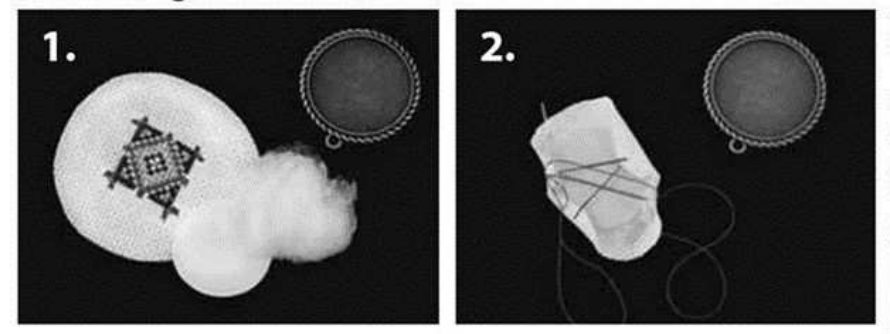

3. Die Größe und Gestalt der Pappe passen Sie an das Medaillonsinnere an. Die Pappe sollte jedoch etwas kleiner als das Medaillon sein, sodass der darauf gelegte bestickte Stoff (samt Füllstoff) ins Medaillon bequem gelegt werden kann.

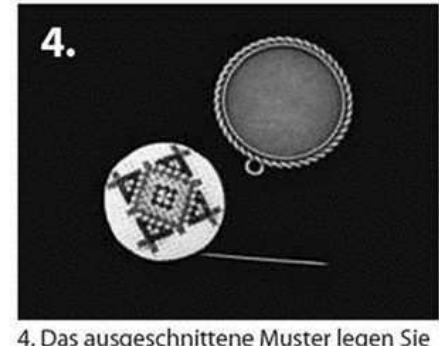

gen Sie auf die Pappe. Dazwischen legen Sie den
Füllstoff. Dann nähen Sie alles zusammen, wie Sie das auf dem Foto 3 sehen können.

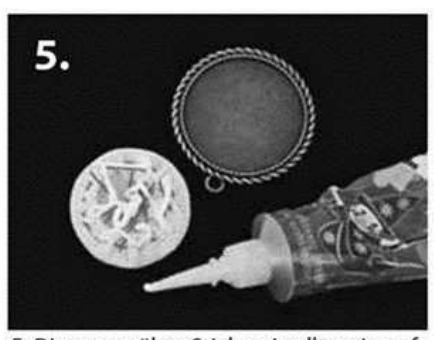

5. Die angenähte Stickerei sollte wie auf dem Foto 4 aussehen.
1. 1. Wählen Sie ein beliebiges Muster und sticken es.

2. Schneiden Sie es aus, indem Sie die Gestalt des Stoffs an den ausgewählten Anhänger anpassen - rechnen Sie 1-1,5 $\mathrm{cm}$ mehr Stoff zum Zusammennähen hinzu.
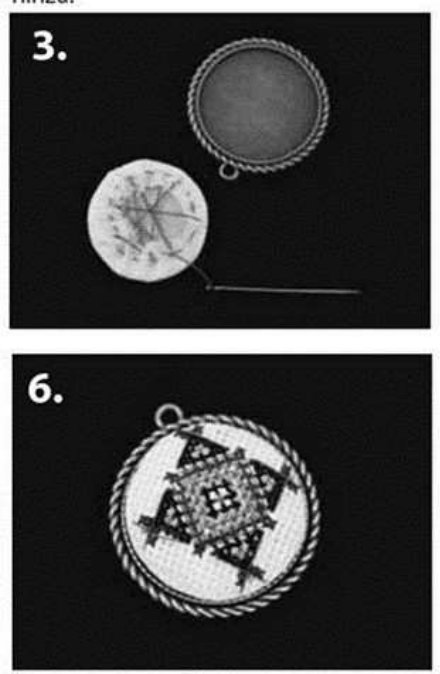

6. Das Zierelement des Medaillons kleben Sie an den Metallanhänger mit Klebstoff an. Drücken Sie es zu und lassen es trocken werden.

Рис. 3. Способ изготовления украшений с микровышивкой с использованием металлической фурнитуры с лотком для вставки

Согласно данному способу из плотного картона вырезают кабошон и из тонкого синтепона - объемную прокладку, соответствующую размерам лотка для вставки. На ткани выполняют вышивку, намечают контур в соответствии с размерами кабошона, вырезают деталь с вышивкой по линии, отстоящей на 1 см от контура кабошона. Примерно на расстоянии 5 мм от намеченного контура кабошона прокладывают ручную строчку прямыми стежками. Далее на кабошон накладывают деталь объемной прокладки (чтобы не было смещения, эти детали можно приклеить друг к другу). Затем совмещают кабошон и ткань с вышивкой таким образом, чтобы объемная прокладка оказалась между ними. Стягивают 
строчку так, чтобы кабошон был ровно обтянут тканью и вышитый элемент располагался строго по центру; нитку закрепляют и обрезают. Обтянутый тканью с вышивкой кабошон вклеивают в лоток для вставки на металлической фурнитуре. При этом способе возможны сложности с точным изготовлением кабошона или с подбором готового кабошона нужного размера; необходимость в припусках на обтягивание кабошона приводит к увеличению расхода ткани для вышивки.

Общим недостатком описанных способов является отсутствие какой-либо защиты вставки с вышивкой от внешних загрязнений в процессе эксплуатации украшений (многочисленные прикосновения рук, пыль).

Целью данного исследования является разработка способа изготовления украшения с микровышивкой с высокими эстетическими и эксплуатационными характеристиками.

Результаты исследования. Практическая значимость предлагаемого способа заключается в разработке технологии изготовления текстильной вставки с вышивкой и непосредственно сборки украшения с защитным покрытием от загрязнений.

Указанный технический результат достигают способом изготовления текстильной вставки с микровышивкой, пакет которой состоит из основного материала, прокладок из материала с односторонним клеевым покрытием и отделочной нитки (рис. 4).

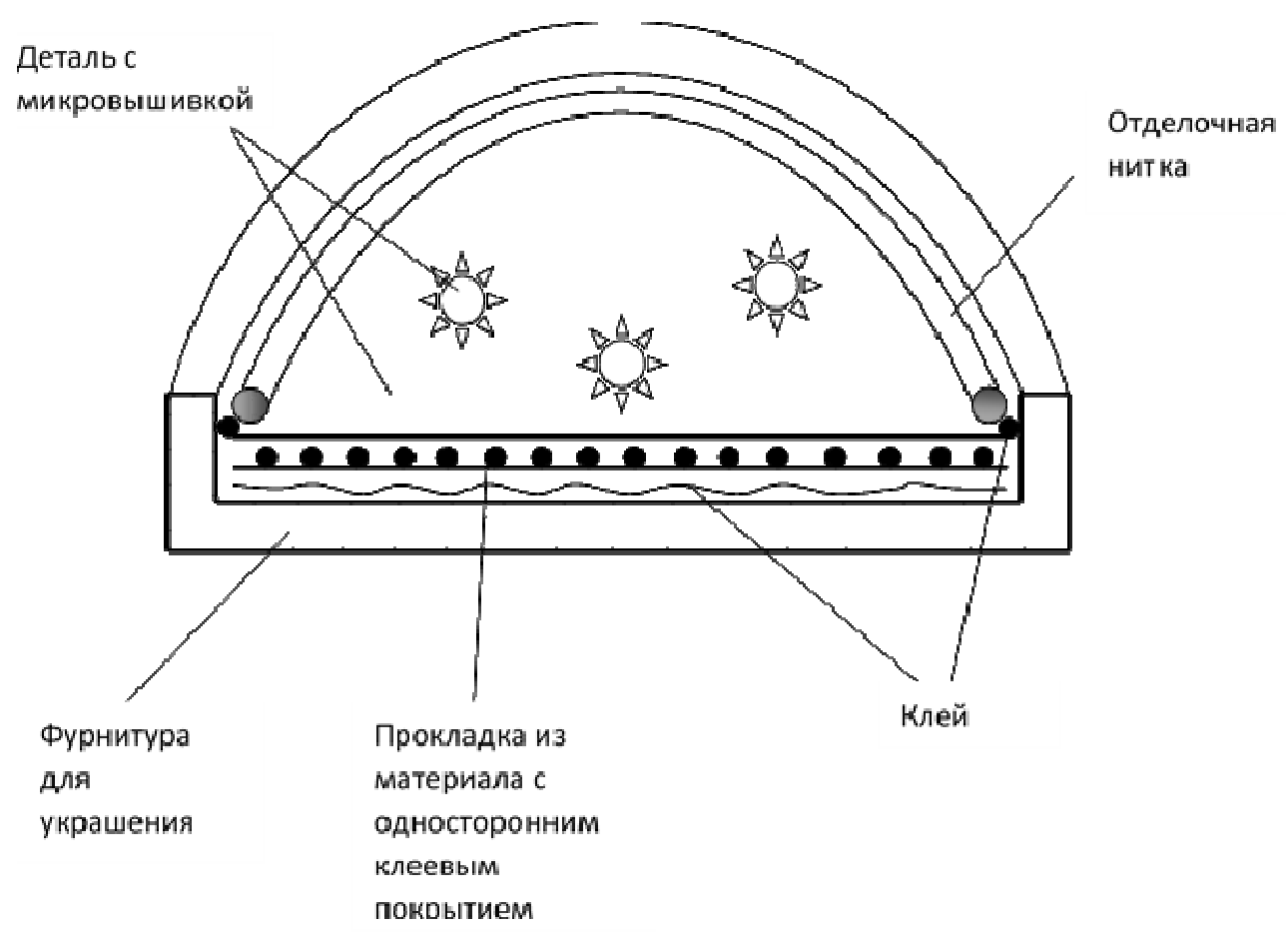

Рис. 4. Схема предлагаемого способа изготовления текстильной вставки с микровышивкой 
При осуществлении разработанного способа микровышивка крестиком выполняется на детали из основного материала - ткани равномерного переплетения для вышивки (рис. 5, операция 1).

Для заправки в пяльцы среднего размера (диаметром 14 см) используется вспомогательная деталь из хлопчатобумажной ткани с «окошком» 8,5x8,5 см, на которую наметывается деталь для вышивки (ее размер равен размеру «окошка» плюс припуски 1 см с каждой стороны детали для вышивки, то есть 9,5х9,5 см). Отсутствие припусков на обтягивание кабошона дает возможность располагать вышитые элементы максимально близко друг к другу и позволяет минимизировать расход основного материала на одно изделие. В процессе выполнения вышивки нитка в начале и в конце работы закрепляется двумя стежками в стороне от области вышивки мотива, что позволяет экономить время на закрепление нити традиционным способом [11]. После завершения вышивки удаляют строчки наметывания детали для вышивки, вынимают деталь из «окошка», все нитки вышивки «выводят» на изнаночную сторону и срезают примерно на расстоянии 2 мм от поверхности детали. Далее смоченной в воде кисточкой (или пальцем) концы ниток направляют к центру вышитого мотива, при этом с лицевой стороны нитки не должны просматриваться за границами вышивки. Далее вышивку приутюживают с изнаночной стороны, закрепляя концы ниток в заданном направлении. Затем вышивку стабилизируют, используя деталь (детали) прокладки из материала с односторонним клеевым покрытием на трикотажной основе (рис. 5 , операция 2).

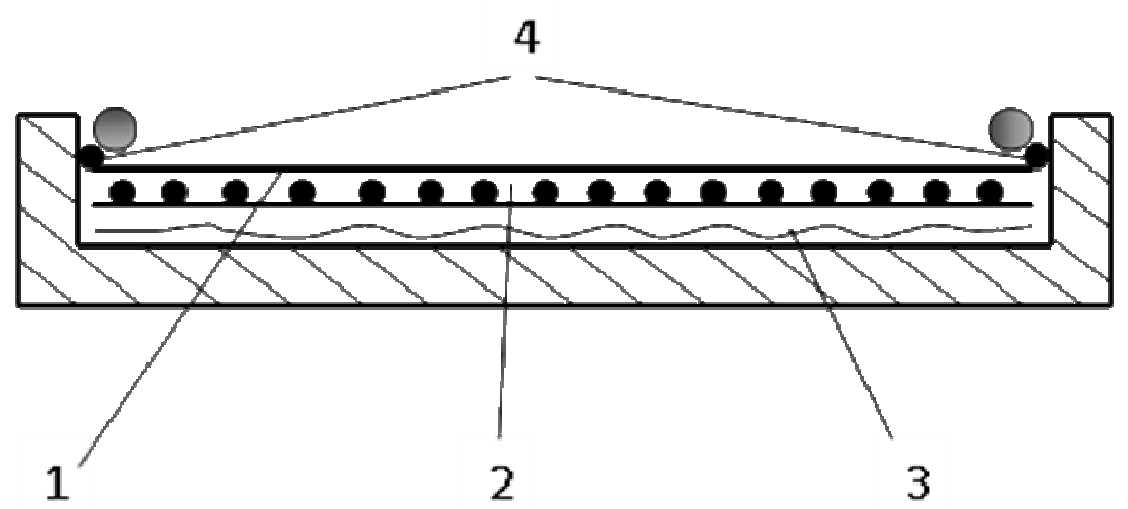

Рис. 5. Проекционная схема способа микровышивки крестиком на детали из основного материала - ткани равномерного переплетения для вышивки

Таким образом, происходит надежное закрепление обрезанных концов нитей, облегчается выполнение дальнейших операций по вырезанию и вклеиванию сформированной вставки с вышивкой в лоток фурнитуры, осуществляется защита от осыпания срезов вставки с вышивкой (поэтому выбрана трикотажная основа прокладки, а не тканая), обеспечиваются высокие эстетические характеристики готового изделия. Наличие прокладки из материала с односторонним клее- 
вым покрытием также предохраняет вышивку от миграции (проникновения) клея на лицевую сторону вставки с вышивкой во время ее крепления к фурнитуре. Количество слоев прокладочного материала зависит от высоты бортика лотка фурнитуры (чем выше бортик, тем больше слоев деталей прокладки). Это необходимо для нивелирования резкого перепада между краем бортика лотка и толщиной детали вставки. Далее изготавливают шаблон из кальки, индивидуально для каждого вида фурнитуры в соответствии с размерами лотка для вставки. На шаблоне рекомендуется разметить середину линиями сгибов в продольном и поперечном направлениях. Шаблон накладывают на вышитый мотив, совмещая центры шаблона и вышивки, и обводят вдоль края шаблона тонким водорастворимым маркером.

Вставку с микровышивкой вырезают по внутренней линии контура обвода. Контур обвода вырезанной детали при необходимости корректируют до полного и точного совпадения с размерами лотка фурнитуры. Затем удаляют видимые остатки маркера смоченной в воде кисточкой. После полного высыхания текстильной вставки с микровышивкой наносят клей на дно лотка фурнитуры тонким слоем и приклеивают вставку с микровышивкой (рис. 5, операция 3), в общем случае соблюдая расположение нитей основы и утка строго по вертикали/горизонтали, в частном - центрируя по рисунку. Клей рекомендуется выбирать только прозрачный и водостойкий, типа «Момент гель». Аккуратно равномерно придавливают вставку с микровышивкой по всей поверхности, излишки клея удаляют влажной салфеткой. В предлагаемом способе используют отделочную нитку по краю вставки - нитка закрывает место стыковки фурнитуры и среза вставки, позволяет реализовать вариативное художественное оформление за счет подбора необходимого цвета (рис. 5, операция 4). Таким образом обеспечивается эстетическое восприятие украшения на более высоком уровне. В качестве отделочной нитки рекомендуются хлопчатобумажные $(№ 20,30)$ или армированные нитки (65 ЛХ), применяемые для выполнения отделочных строчек в джинсовых изделиях [12]. Отделочную нитку приклеивают следующим способом. Небольшое количество клея нанести на толстую иглу с тупым концом и с ее помощью перенести клей вдоль линии стыковки среза вставки и фурнитуры. Далее участками по 1-1,5 см приклеить отделочную нитку по всему периметру лотка для вставки. Срезы начала и конца отделочной нитки выполнить под углом для минимизации толщины в месте их стыковки. Далее оставить украшение до полного высыхания клея.

Для обеспечения защиты текстильной вставки с микровышивкой от загрязнений во время эксплуатации и длительного хранения украшения предлагается использовать текстурный гель $[13,14]$. Гель нанести на вставку с микровышивкой по всей поверхности с помощью кисточки. Проникая в поры ткани и ниток, гель обеспечивает защиту вставки с микровышивкой от пыли, а также возможных загрязнений от внешнего воздействия во время эксплуатации. После нанесения текстурного геля цвета и полутона вышивки приобретают более глубокую насыщенность. Гель является дополнительной защитой изображения от возможных ссадин и других повреждений в процессе его «жизни». 
После полного высыхания текстурного геля и окончательной сборки изделия с применением необходимой дополнительной фурнитуры (цепочек, замочков и прочего) украшение готово к использованию.

\section{Выводы}

Таким образом, предлагаемый способ обеспечивает изготовление украшения с микровышивкой посредством вклеивания текстильной вставки с микровышивкой в лоток фурнитуры, без использования дополнительной детали (кабошона), с более экономичным расходом основного материала (ткани для вышивки), с защитным покрытием от загрязнений текстурным гелем, при этом возможно применение более вариативного художественного оформления украшений за счет применения отделочной нитки.

1. Значение слова «прекрасное».- Текст: электронный // booksite.ru: [сайт]. - URL: https://www.booksite.ru/fulltext/1/001/ 008/092/446.htm (дата обращения: 11.11.2021).

2. Текеева 3.Х., Текеева Л. К. Традиционная культура и быт народов России: курс лекций. - Карачаевск, 2019. - 448 с.

3. Микровышивка - история и современность. - Текст: электронный // styledst.ru: [сайт]. URL: http://styledst.ru/zhurnal/mikrovyshivka-istorija-i-sovremennost/ (дата обращения: 11.11.2021).

4. Микровышивка - особенности техники. - Текст: электронный // tailors.com: [сайт]. URL: https://tailors.com.ua/blogs/mikrovyshivka-osobennosti-tekhniki (дата обращения: 11.11.2021)

5. Бобрович Г. А., Бобрович Н. А. Традиции и современные технологии вышивки на Витебщине // Современное технологическое образование: опыт, инновации, перспективы: сборник материалов III Международной научно-практической конференции. Липецк, 2020. - С. 83-86.

6. Жаринова Н. О. Вышивка атласными лентами как средство приобщения ребенка к традициям художественной культуры // Образовательная среда: постижение культурно-исторической реальности: сборник научных статей. - Санкт-Петербург: Изд-во РГПУ им. А.И. Герцена, 2019. - С. 530-532.

7. Шибаева В. А., Лебедева Т. В., Колодий-Тяжов Л. А. Разработка и изготовление ювелирных украшений с использованием техники сутажной вышивки // Научные исследования и разработки в области дизайна и технологий: материалы Всероссийской научно-практической конференции. - Кострома, 2021. - С. 68-71.

8. Broche ou Pingente Passo a Passo. - Текст: электронный // pinterest.ru: [сайт]. - URL: https://www.pinterest.ru/pin/362469470007658868/ (дата обращения: 11.11.2021).

9. Журналы «Вышиванка». - Текст: электронный // passionforum.ru: [сайт]. - Вып. 104 (2). - C. 8. - URL: https://www.passionforum.ru/posts/76006-zhurnaly-vyshivanka.html (дата обращения: 11.11.2021).

10. Журнал «DEIN KREUZSTICH MAGAZIN». - Текст: электронный // liveinternet.ru: [сайт]. - 2017. - № 4. - C. 38. - URL: https://www.liveinternet.ru/users/ 4606978/post459211747/ (дата обращения: 11.11.2021).

11. Журнал «Вышиваю крестиком». - Текст: электронный // vushivki.ru: [сайт]. - 2012. № 11 (99). - C. 60. - URL: http://vushivki.ru/vushivayu_krestikom/1418-zhurnal-povyshivke-vyshivayu-krestikom-1199-2012.html

12. Материаловедение (дизайн костюма) / Е.А. Кирсанова, Ю.С. Шустов, А.В. Куличенко [и др.]. - Москва, 2019. - С. 329. 
13. Текстурный гель. - Текст: электронный // posterhd.ru: [сайт]. - URL: https://posterhd.ru/articles/27-teksturniy-gel (дата обращения: 11.11.2021).

14. Для чего нужно покрывать постеры и картины текстурным гелем и как это происходит? - Текст: электронный // posterhd.ru: [сайт]. - URL: https://artdecory.ru/texturegel.html (дата обращения: 11.11.2021).

\section{Транслитерация}

1. Znachenie slova «prekrasnoe». - Tekst: elektronnyj // booksite.ru: [sajt]. - URL: https://www.booksite.ru/fulltext/1/001/ 008/092/446.htm (data obrashcheniya: 11.11.2021).

2. Tekeeva Z.H., Tekeeva L. K. Tradicionnaya kul'tura i byt narodov Rossii: kurs lek-cij. Karachaevsk, 2019. - 448 s.

3. Mikrovyshivka - istoriya i sovremennost'. - Tekst: elektronnyj // styledst.ru: [sajt]. URL: http://styledst.ru/zhurnal/mikrovyshivka-istorija-i-sovremennost/ (data obrashcheniya: 11.11.2021).

4. Mikrovyshivka - osobennosti tekhniki. - Tekst: elektronnyj // tailors.com: [sajt]. - URL: https://tailors.com.ua/blogs/mikrovyshivka-osobennosti-tekhniki (data obrashcheniya: 11.11.2021).

5. Bobrovich G. A., Bobrovich N. A. Tradicii i sovremennye tekhnologii vyshivki na Vitebshchine // Sovremennoe tekhnologicheskoe obrazovanie: opyt, innovacii, perspektivy: sbornik materialov III Mezhdunarodnoj nauchno-prakticheskoj konferencii. - Lipeck, 2020. - S. 83-86.

6. Zharinova N. O. Vyshivka atlasnymi lentami kak sredstvo priobshcheniya rebenka k tradiciyam hudozhestvennoj kul'tury // Obrazovatel'naya sreda: postizhenie kul'turnoistoricheskoj real'nosti: sbornik nauchnyh statej. - Sankt-Peterburg: Izd-vo RGPU im. A.I. Gercena, 2019. - S. 530-532.

7. Shibaeva V. A., Lebedeva T. V., Kolodij-Tyazhov L. A. Razrabotka i izgotovlenie yuvelirnyh ukrashenij s ispol'zovaniem tekhniki sutazhnoj vyshivki // Nauchnye issledovaniya i razrabotki $\mathrm{v}$ oblasti dizajna $\mathrm{i}$ tekhnologij: materialy Vserossijskoj na-uchnoprakticheskoj konferencii. - Kostroma, 2021. - S. 68-71.

8. Broche ou Pingente Passo a Passo. - Tekst: elektronnyj // pinterest.ru: [sajt]. - URL: https://www.pinterest.ru/pin/362469470007658868/ (data obrashcheniya: 11.11.2021).

9. Zhurnaly «Vyshivanka». - Tekst: elektronnyj // passionforum.ru: [sajt]. - Vyp. 104 (2). S. 8. - URL: https://www.passionforum.ru/posts/76006-zhurnaly-vyshivanka.html (data obrashcheniya: 11.11.2021).

10. ZHurnal «DEIN KREUZSTICH MAGAZIN». - Tekst: elektronnyj // liveinternet.ru: [sajt]. - 2017. - № 4. - S. 38. - URL: https://www.liveinternet.ru/users/ 4606978/post459211747/ (data obrashcheniya: 11.11.2021).

11. ZHurnal «Vyshivayu krestikom». - Tekst: elektronnyj // vushivki.ru: [sajt]. - 2012. -№ 11 (99). - S. 60. - URL: http://vushivki.ru/vushivayu_krestikom/1418-zhurnal-povyshivke-vyshivayu-krestikom-1199-2012.html

12. Materialovedenie (dizajn kostyuma) / E. A. Kirsanova, Yu.S. Shustov, A. V. Kulichenko [i dr.]. - Moskva, 2019. - S. 329.

13. Teksturnyj gel'. - Tekst: elektronnyj // posterhd.ru: [sajt]. - URL: https://posterhd.ru/articles/27-teksturniy-gel (data obrashcheniya: 11.11.2021).

14. Dlya chego nuzhno pokryvat' postery i kartiny teksturnym gelem i kak eto proiskhodit? Tekst: elektronnyj // posterhd.ru: [sajt]. - URL: https://artdecory.ru/texture-gel.html (data obrashcheniya: 11.11.2021). 
(С) Л.А. Королева, 2021

(C) А.В. Подшивалова, 2021

Для цитирования: Королева Л.А., Подшивалова А. В. Разработка способа изготовления украшения с микровышивкой с высокими эстетическими и эксплуатационными характеристиками // Территория новых возможностей. Вестник Владивостокского государственного университета экономики и сервиса. - 2021. - Т. 13, № 4. - С. 177-188.

For citation: Koroleva L. A., Podshivalova A. V. Development of a method for manufacturing micro-embroidered jewelry with high aesthetic and operational characteristics, The Territory of New Opportunities. The Herald of Vladivostok State University of Economics and Service, 2021, Vol. 13, № 3, pp. 177-188.

DOI https://doi.org/10.24866/VVSU/2073-3984/2021-4/177-188

Дата поступления: $\quad$ Одобрена после рецензирования: 12.11.2021
18.11 .2021

Принята к публикации: 22.11.2021 